\title{
Fatores socioeconômicos que influenciam na disposição de consumidores em adquirir carne bovina com certificação de origem em Belo Horizonte, Minas Gerais, Brasil
}

\author{
Socio-economic factors affecting the consumer provision in meat with \\ certification of origin Belo Horizonte, Minas Gerais, Brazil
}

\section{Danielle Rodrigues Magalhães ${ }^{1}$, Marcos Aurélio Lopes ${ }^{1 *}$, Christiane Maria Barcellos Magalhães da Rocha', Fábio Raphael Pascoti Bruhn², Jerry Carvalho Borges ${ }^{1}$, Christiano França da Cunha ${ }^{3}$}

RESUMO: Objetivou-se verificar a influência dos fatores socioeconômicos na disposiçáo de 407 consumidores em hipermercados do município de Belo Horizonte, Minas Gerais, em adquirir carne bovina com certificação de origem e verificar as características inerentes ao produto que auxiliam o consumidor no momento da compra, considerando o seu conhecimento prévio sobre rastreabilidade e certificação de origem. Foi realizada uma análise descritiva de todas as variáveis e, posteriormente, realizada a análise univariada pelo teste do qui-quadrado ou exato de Fischer. As variáveis foram adicionadas no modelo múltiplo da regressão logística Generalized Estimating Equations (GEE) e para todas as variáveis presentes no modelo final $(\mathrm{p} \leq 0,05)$ foi calculado o risco por meio da odds ratio (OR) ajustada a um intervalo de confiança de $95 \%$. Todos os fatores socioeconômicos analisados (sexo, idade, renda e escolaridade) influenciaram na disposição de consumidores em adquirir carne bovina com certificaçáo de origem. Os atributos intrínsecos mais importantes na tomada de decisão no momento da compra da carne foram cor, maciez, odor e a pouca quantidade de gordura; enquanto que os atributos extrínsecos foram preço, selo de qualidade e carimbo do SIF. A maioria dos consumidores conhece o conceito correto de rastreabilidade e acreditam que o maior benefício da carne rastreada é oferecer mais segurança e evitar riscos de doenças transmitidas pelos alimentos; e a desvantagem é ser um produto mais caro do que o convencional.

PALAVRAS-CHAVE: atributos da carne; certificação de origem; rastreabilidade; rótulo.

\begin{abstract}
The present study aimed to verify the influence of socioeconomic factors in the provision of 407 consumers in supermarkets in the city of Belo Horizonte, Minas Gerais, Brazil, in purchasing beef with certification of origin and to verify the inherent characteristics of the product that help the consumer at the time of purchase, considering their prior knowledge about traceability and certification of origin. A descriptive analysis of all variables was performed and a univariate analysis was subsequently conducted by chi-square test. The variables were added in the multiple logistic regression model Generalized Estimating Equations (GEE), and for all variables in the final model $(\mathrm{p} \leq 0.05)$ the risk was calculated by the adjusted odds ratio (OR) to a range of $95 \%$ confidence. All socioeconomic factors examined (gender, age, income and education) influence the willingness of consumers to purchase beef with certification of origin. The most important intrinsic attributes in decision making when buying meat were the color, softness, odor and little amount of fat, whereas the extrinsic attributes were price, quality seal and stamp of the SIF. Most of the consumers know the correct concept of traceability and believe that the greatest benefit of the traced meat is to be safer and to avoid the risk of foodborne illness; and the disadvantage is to be a more expensive product than the conventional.
\end{abstract}

KEYWORDS: meat attributes; certification of origin; traceability; label. 


\section{INTRODUÇÃO}

Desde a crise de Bovine Spongiform Encephalopathy (BSE), ou doença da "vaca louca", na Inglaterra em 1996, os consumidores passaram a exigir garantias que assegurem a inocuidade dos alimentos. O sistema de rastreabilidade surgiu como um meio de transmitir transparência em toda a cadeia produtiva e contribuir para a segurança alimentar (Furquim, 2012).

A palavra rastreabilidade indica a capacidade para acompanhar o percurso de um produto ou de conhecer o seu processo de produção, manipulaçấo, transformação, embalagem ou expedição. Rastreabilidade animal consiste no acompanhamento de todos os eventos ocorridos durante a vida de um animal, ou seja, é o registro de todas as ocorrências, manejos e movimentaçôes ocorridas desde seu nascimento ou identificação até o abate, momento esse que se estende até o consumo de suas partes (CAIXETA et al., 2014).

A exigência dos mercados importadores buscando cada vez mais produtos de qualidade, sem risco sanitário, provocou uma mudança de atitude no segmento industrial da carne bovina no Brasil. Para se adequar às normas impostas pelo cenário mundial, principalmente pela Uniáo Europeia (UE), o Ministério da Agricultura, Pecuária e Abastecimentos (MAPA) (BRASIL, 2002) criou o Sistema Brasileiro de Identificação e Certificação de Origem Bovina e Bubalina (SISBOV). Atualmente, vigoram as Instruçôes Normativas no 17 (BRASIL, 2006) e no 65 (Brasil, 2009a) e a Lei no 12.097 , de 24 de novembro de 2009 (BRASIL, 2009b), que foi regulamentada pelo decreto no 7.623 , de 22 de novembro de 2011.

O Brasil ocupa posição de destaque no agronegócio e sua participação no mercado mundial de carnes depende da adequação constante às demandas crescentes, e cada vez mais restritivas, exigentes e específicas dos seus mercados consumidores. Nesse contexto, a rastreabilidade bovina, se gerenciada pela cadeia da carne de forma adequada, demonstra que não é apenas uma barreira protecionista dos mercados consumidores, mas sim, uma ferramenta para aumentar a segurança alimentar e a garantia ao consumidor, trazendo consigo benefícios sociais e econômicos para as áreas produtoras (ABIEC, 2011).

A consolidação do sistema de rastreabilidade é fundamental para os consumidores, pois as informaçôes de origem da carne podem incentivar a tomada de decisáo no processo de aquisiçấo do produto. Porém, a oferta de carne com certificação no mercado varejista ainda é pequena, o que causa a falta de incentivo de adesáo dos pecuaristas ao programa de rastreabilidade brasileiro (Lopes; SANTOs, 2007).

Para que ocorra a expansão do mercado da carne rastreada, no Brasil, é preciso verificar a disposição dos consumidores em adquirir a carne com certificação e analisar o seu conhecimento com relaçáo aos conceitos sobre rastreabilidade e certificação de origem, pois é necessário conhecimento sobre a importância da carne com certificaçáo para a promoção de um aumento na procura por esse produto. É preciso, ainda, verificar a disposiçẫo dos consumidores em pagar mais caro por ter "garantia" de melhor qualidade.

Vários pesquisadores têm estudado o tema rastreabilidade bovina, abordando diferentes aspectos e implicaçóes. No entanto, é importante ressaltar a escassez de resultados de pesquisas brasileiras sobre o consumo de carne rastreada ou certificada, deixando uma lacuna no conhecimento para que novos estudos sejam elaborados, o que reforça a necessidade para a realização desse tipo de estudo no país. Assim, o objetivo deste trabalho foi analisar a influência dos fatores socioeconômicos na disposição de consumidores em adquirir carne bovina com certificaçấo de origem e verificar as características inerentes ao produto que os auxiliam no momento da compra, considerando o seu conhecimento prévio sobre rastreabilidade e certificaçáo de origem.

\section{MATERIAL E MÉTODOS}

Foi realizada uma pesquisa com uma amostra de 407 consumidores em três hipermercados, que comercializam carne com certificação de origem, em diferentes bairros Belo Horizonte, Minas Gerais, em setembro de 2012. Foi aplicado um questionário qualitativo estruturado contendo 12 questôes de múltipla escolha, relacionadas às atitudes e à percepçáo dos consumidores de carne. As entrevistas foram aplicadas aos indivíduos enquanto estes se encontravam à frente da gôndola das carnes. Essas questôes foram aplicadas apenas aos consumidores familiarizados com a definiçấo de rastreabilidade e certificação de origem. Àqueles que relataram desconhecer o termo carne rastreada ou com certificaçáo de origem, a entrevista se restringia às questôes socioeconômicas. Assim, foi questionado se consomem carne com certificação de origem, sobre o que acreditam ser o(s) fator(res) mais importante(s) na tomada de decisão na compra da carne, qual o conceito correto de carne rastreada, quais os benefícios e desvantagens que a carne com certificação tem em relação à carne sem certificação, se estão dispostos a pagar mais pela carne com certificação de origem e qual o percentual de aumento admissível que poderia incidir sobre a produto. Visando evitar possíveis vieses de informação, todas essas perguntas foram realizadas sem que o entrevistado tivesse acesso ao formulário de questôes, sendo inquirido e posteriormente assinalado, pelo entrevistador, a opção mais adequada de acordo com a resposta fornecida.

Para identificar as características associadas à percepção e atitude dos consumidores sobre a carne rastreada foi feita a análise descritiva de todas as variáveis e ressaltadas as maiores frequências a fim de traçar o perfil dos consumidores estudados. Posteriormente, foi realizada a análise univariada pelo teste do qui-quadrado ou exato de Fischer. As variáveis que apresentaram associação com $\mathrm{p} \leq 0,2$ pelo teste do qui-quadrado ou exato de Fischer foram selecionadas para a construção do modelo múltiplo, como no estudo de Rocha et al. (2011). 
A existência de associação entre os fatores foi verificada utilizando o modelo múltiplo Generalized Estimating Equations (GEE). Para todas as variáveis presentes no modelo final $(\mathrm{p} \leq 0,05)$ foi calculado o risco por meio da odds ratio (OR) ajustada e seu intervalo de confiança de 95\% (IC95\%).

\section{RESULTADOS E DISCUSSÃO}

Dos 407 consumidores entrevistados em 3 hipermercados que comercializam carne com garantia de origem, no município de Belo Horizonte, Minas Gerais, 246 (60,44\%) conhecem sobre rastreabilidade, carne rastreada ou certificação de origem e $43,90 \%$ afirmaram que consomem carne bovina com certificaçáo de origem. A maior parte dos consumidores entrevistados é do sexo masculino (51,35\%), com até 40 anos de idade $(53,32 \%)$, renda de até 6 salários mínimos $(65,27 \%)$ e apresentava escolaridade de até segundo grau completo $(52,97 \%)$. Do total de entrevistados, $24(5,90 \%)$ não quiseram responder sua renda familiar e $3(0,74 \%)$ não informaram o grau de escolaridade. Dentre aqueles que conhecem sobre certificação de origem, 19 (7,72\%) não responderam sua renda familiar e 1 consumidor $(0,41 \%)$ náo informou a escolaridade.

Neste estudo foi demonstrado que o sexo está associado a diversas atitudes e percepçóes dos consumidores com relaçáo à carne bovina com certificação de origem (Tabela 1). Os entrevistados que consomem carne rastreada são, em sua maioria (52,50\%), do sexo feminino. As mulheres têm 1,989 vezes mais chance de consumir carne bovina com certificação de origem do que os homens. Valores semelhantes foram obtidos por VelHo et al. (2009), ao constatarem que $50,90 \%$ das mulheres e $41,40 \%$ dos homens, no momento da compra, preferem que a carne tenha certificado de origem.

As características extrínsecas do rótulo e intrínsecas da carne bovina são motivos determinantes para a tomada de decisão no momento da compra. $\mathrm{O}$ atributo extrínseco selo de qualidade é responsável pela tomada de decisão da compra por $69,16 \%$ mulheres e $56,34 \%$ dos homens. Já os atributos intrínsecos que levam o consumidor a tomar sua decisão de compra é a observação da cor para $93,33 \%$ das mulheres e $80,95 \%$ dos homens; em seguida, a maciez e textura da carne para $89,17 \%$ dos consumidores do sexo feminino e $77,78 \%$ do sexo masculino; também é levado em consideração o odor da carne para $88,33 \%$ das mulheres e $75,40 \%$ dos homens; e, por fim, a pouca quantidade de gordura, que para $67,50 \%$ das mulheres e apenas $32,54 \%$ dos homens é um atributo importante na tomada de decisão no momento da compra. As chances de uma mulher tomar sua decisão de compra com base na cor da carne é 3,327 vezes maior do que de um homem, e as chances de uma mulher escolher uma carne pela menor quantidade de gordura é 4,293 vezes maior do que a escolha de um homem (Tabela 1).

Apesar dos entrevistados do sexo masculino acreditarem que as características extrínsecas e intrínsecas da carne são importantes no momento da compra, para as mulheres esses atributos têm um valor ainda maior. Isso pode ser explicado, segundo VerbeKe; WARD (2006), pelo fato de que as pessoas

Tabela 1. Questões sobre o consumo de carne bovina por consumidores que conhecem o termo carne rastreada associadas ao sexo, em três supermercados de Belo Horizonte, Minas Gerais, Brasil, em setembro de 2012.

\begin{tabular}{|c|c|c|c|c|c|c|c|}
\hline \multirow[t]{2}{*}{ Questão levantada* } & \multirow[t]{2}{*}{ Sexo } & \multicolumn{2}{|c|}{$\begin{array}{l}\text { Categorias de } \\
\text { respostas }\end{array}$} & \multirow[t]{2}{*}{ Total } & \multirow[t]{2}{*}{ Valor $\mathrm{p}$} & \multirow{2}{*}{$\begin{array}{l}\text { Odds } \\
\text { ratio }\end{array}$} & \multirow[t]{2}{*}{ IC95\% } \\
\hline & & Não & $\operatorname{Sim}(\%)$ & & & & \\
\hline \multirow{2}{*}{ Consumo de produtos de origem animal com certificação** } & M & 81 & $45(35,71)$ & 126 & \multirow{2}{*}{0,008} & 1 & \multirow{2}{*}{$\begin{array}{l}1,193- \\
3,316\end{array}$} \\
\hline & $\mathrm{F}$ & 57 & $63(52,5)$ & 120 & & 1,989 & \\
\hline \multirow{2}{*}{$\begin{array}{l}\text { Motivo de tomada de decisão de compra: } \\
\text { selo de qualidade** }\end{array}$} & M & 55 & $71(56,34)$ & 126 & \multirow{2}{*}{0,028} & 1 & \multirow{2}{*}{$\begin{array}{l}1,069- \\
3,117\end{array}$} \\
\hline & $\mathrm{F}$ & 37 & $83(69,16)$ & 120 & & 1,825 & \\
\hline \multirow{2}{*}{ Motivo de tomada de decisão de compra: $\operatorname{cor}^{* *}$} & M & 24 & $102(80,95)$ & 126 & \multirow{2}{*}{0,005} & 1 & \multirow{2}{*}{$\begin{array}{l}1,430- \\
7,738\end{array}$} \\
\hline & $\mathrm{F}$ & 8 & $112(93,33)$ & 120 & & 3,327 & \\
\hline \multirow{2}{*}{ Motivo de tomada de decisão de compra: maciez e textura** } & M & 28 & $98(77,78)$ & 126 & \multirow{2}{*}{0,025} & 1 & \multirow{2}{*}{$\begin{array}{r}1,108- \\
4,641\end{array}$} \\
\hline & $\mathrm{F}$ & 13 & $107(89,17)$ & 120 & & 2,268 & \\
\hline \multirow{2}{*}{ Motivo de tomada de decisão de compra: odor** } & M & 31 & $95(75,40)$ & 126 & \multirow{2}{*}{0,019} & 1 & \multirow{2}{*}{$\begin{array}{l}1,148- \\
4,623\end{array}$} \\
\hline & $\mathrm{F}$ & 14 & $106(88,33)$ & 120 & & 2,304 & \\
\hline \multirow{2}{*}{$\begin{array}{l}\text { Motivo de tomada de decisão de compra: } \\
\text { pouca quantidade de gordura** }\end{array}$} & M & 85 & $41(32,54)$ & 126 & \multirow{2}{*}{0,000} & 1 & \multirow{2}{*}{$\begin{array}{r}2,446 \\
7,535\end{array}$} \\
\hline & $\mathrm{F}$ & 39 & $81(67,50)$ & 120 & & 4,293 & \\
\hline \multirow{2}{*}{$\begin{array}{l}\text { Conceito de rastreabilidade: aquela que traz informações } \\
\text { relacionadas ao sistema de produção e origem do animal** }\end{array}$} & M & 49 & $77(61,11)$ & 126 & \multirow{2}{*}{0,05} & 1 & \multirow{2}{*}{$\begin{array}{r}0,326- \\
1,012\end{array}$} \\
\hline & $\mathrm{F}$ & 63 & $57(47,50)$ & 120 & & 0,574 & \\
\hline \multirow{2}{*}{$\begin{array}{l}\text { Conceito de rastreabilidade: aquela fiscalizada pelo sistema } \\
\text { de inspeção federal ou estadual }{ }^{* *}\end{array}$} & $M$ & 54 & $72(57,14)$ & 126 & \multirow{2}{*}{0,005} & 1 & \multirow{2}{*}{$\begin{array}{r}1,283- \\
3,919\end{array}$} \\
\hline & $\mathrm{F}$ & 39 & $90(75,00)$ & 120 & & 2,242 & \\
\hline
\end{tabular}

IC95\%: intervalo de confiança de 95\%; *regressão logística múltipla estimada por Generalized Estimation Equations; constam apenas os fatores que permaneceram com associação estatisticamente significativa no modelo final $(p \leq 0,05)$; ${ }^{* *} n=246$; apenas aqueles entrevistados que responderam que já tinham ouvido falar em carne rastreada foram considerados no modelo. 
do sexo feminino tendem a prestar mais atenção ao rótulo, em comparação às do sexo masculino.

A importância do selo de qualidade, dado como principal atributo extrínseco de tomada de decisão de compra para as mulheres (Tabela 1), é também confirmada por DENEGRi et al. (2010), que observaram que as mulheres dão mais importância ao selo de garantia de qualidade, ainda que o interesse por uma alimentação saudável seja de ambas as partes. BARCELlos et al. (2012), Candia et al. (2010), Velho et al. (2009), Verbeke et al. (2010) e WEZEMAEL et al. (2010) mostraram que várias informações intrínsecas foram mencionadas pelos participantes como sendo um sinal de segurança alimentar, como cor, textura e teor de gordura, assumindo que o aspecto do produto é também um indicativo de que o mesmo é seguro.

No entanto, contradizendo os resultados encontrados sobre a maciez da carne, neste trabalho, LOUREIRO; UMBERGER (2007) verificaram que a maciez não foi caracterizada como um atributo de qualidade da carne, apesar de outros pesquisadores anteriormente demonstrarem ser a maciez um atributo muito valorizado pelos consumidores.

O conceito correto de carne rastreada ou com certificação de origem, ou seja, a carne que traz informaçôes relacionadas ao sistema de produção e origem do animal, é conhecido por $61,11 \%$ dos homens. Já para $75 \%$ das mulheres o conceito correto seria aquele na qual a carne é fiscalizada pelo sistema de inspeção federal (SIF) ou estadual (SIE). Esse é um conceito parcialmente correto, porém incompleto, pois toda carne rastreada deve passar por um serviço de inspeção realizado pelos órgãos governamentais, mas não garante que, devido a isso, a carne seja considerada um produto rastreado. Esses resultados assemelharam-se aos encontrados por BARCELlos et al. (2012), que verificaram apenas $47 \%$ dos consumidores pesquisados com conhecimento da certificação de rastreabilidade contra $70,50 \%$ que são conhecedores dos selos de qualidade como
SIF, SIE, CISPOA (Coordenadoria de Inspeção de Produtos de Origem Animal).

Dentre os atributos e perspectivas analisados no fator socioeconômico idade, os entrevistados acima de 41 anos $(32,46 \%)$ atribuíram como característica para tomada de decisão da compra da carne, aquela de rápido e fácil preparo. Eles têm 2,807 vezes mais chances de adquirirem uma carne bovina pelo preparo rápido e fácil do que indivíduos com idade igual ou inferior a 40 anos (Tabela 2). Velho et al. (2009) e VerbeKe et al. (2010) identificaram que as consumidores mais idosos preferem carnes mais macias por facilitar as práticas culinárias como, por exemplo, tempo de cozimento mais curto.

O conceito correto de carne rastreada náo é bem conhecido pelos consumidores em ambas as faixas de idade analisadas. Os consumidores com idade abaixo de 40 anos (59,09\%) e acima de 41 anos $(73,68 \%)$ descrevem como sendo o conceito correto aquela carne fiscalizada pelo SIF e SIE (Tabela 2). Para Loureiro; Umberger (2007), os atributos que mais entrevistados associaram como sendo um alimento seguro eram aqueles que carregavam no rótulo uma garantia de que a carne foi inspecionada por algum órgão governamental ligado a segurança alimentar.

Para 56,82\% dos entrevistados com idade inferior a 40 anos, uma desvantagem da carne com certificação de origem é que ela é considerada um produto mais oneroso do que uma carne sem certificação de origem. Mesmo assim, 82,57\% desses consumidores mais jovens e $61,40 \%$ das pessoas com mais idade estão dispostos a pagar mais caro pela carne com certificação de origem. No entanto, nas duas faixas de idade analisadas, para 98,17\% dos consumidores com idade inferior a 40 anos e $90 \%$ com idade superior a 41 anos, o percentual admissível que poderia incidir sobre o produto não poderia exceder 20\% (Tabela 2).

Tabela 2. Questões sobre o consumo de carne bovina por consumidores que conhecem o termo carne rastreada associadas à idade, em três supermercados de Belo Horizonte, Minas Gerais, Brasil, em setembro de 2012.

\begin{tabular}{|c|c|c|c|c|c|c|c|}
\hline \multirow[t]{2}{*}{ Questão levantada* } & \multirow[t]{2}{*}{ Idade } & \multicolumn{2}{|c|}{$\begin{array}{l}\text { Categorias de } \\
\text { respostas }\end{array}$} & \multirow[t]{2}{*}{ Total } & \multirow[t]{2}{*}{ Valor $\mathrm{p}$} & \multirow{2}{*}{$\begin{array}{l}\text { Odds } \\
\text { ratio }\end{array}$} & \multirow[t]{2}{*}{ IC95\% } \\
\hline & & Não & $\operatorname{sim}(\%)$ & & & & \\
\hline \multirow{2}{*}{$\begin{array}{l}\text { Motivo de tomada de decisão de compra: preparo } \\
\text { rápido e fácil** }\end{array}$} & $\leq 40$ anos & 113 & $19(14,39)$ & 132 & \multirow{2}{*}{0,000} & 1 & \multirow{2}{*}{$\begin{array}{l}1,906- \\
4,134\end{array}$} \\
\hline & $>41$ anos & 77 & $37(32,46)$ & 114 & & 2,807 & \\
\hline \multirow{2}{*}{$\begin{array}{l}\text { Conceito de rastreabilidade: aquela fiscalizada pelo } \\
\text { sistema de inspeção federal ou estadual** }\end{array}$} & $\leq 40$ anos & 54 & $78(59,09)$ & 132 & \multirow{2}{*}{0,013} & 1 & \multirow{2}{*}{$\begin{array}{l}1,165- \\
3,580\end{array}$} \\
\hline & $>41$ anos & 30 & $84(73,68)$ & 114 & & 2,042 & \\
\hline \multirow{2}{*}{$\begin{array}{l}\text { Desvantagens da carne com certificação: produto } \\
\text { mais caro** }\end{array}$} & $\leq 40$ anos & 57 & $75(56,82)$ & 132 & \multirow{2}{*}{0,021} & 1 & \multirow{2}{*}{$\begin{array}{c}0,315- \\
0,911\end{array}$} \\
\hline & $>41$ anos & 66 & $48(42,10)$ & 114 & & 0,536 & \\
\hline \multirow{2}{*}{$\begin{array}{l}\text { Disposição em pagar mais caro pela carne bovina } \\
\text { certificada** }\end{array}$} & $\leq 40$ anos & 23 & $109(82,57)$ & 132 & \multirow{2}{*}{0,000} & 1 & $0,149-$ \\
\hline & $>41$ anos & 44 & $70(61,40)$ & 114 & & 0,279 & 0,524 \\
\hline \multirow{2}{*}{$\begin{array}{l}\text { Disposto a pagar até } 20 \% \text { a mais pela carne } \\
\text { certificada*** }\end{array}$} & $\leq 40$ anos & 107 & $2(1,83)$ & 109 & \multirow{2}{*}{0,029} & 1 & \multirow{2}{*}{$\begin{array}{l}1,198- \\
29,502\end{array}$} \\
\hline & $>41$ anos & 63 & $7(10,0)$ & 70 & & 5,944 & \\
\hline
\end{tabular}

IC95\%: intervalo de confiança de 95\%; *regressão logística múltipla estimada por Generalized Estimation Equations; constam apenas os fatores que permaneceram com associação estatisticamente significativa no modelo final ( $\mathrm{p} \leq 0,05)$; ** $n=246$; apenas aqueles entrevistados que responderam que já tinham ouvido falar em carne rastreada foram considerados no modelo; ${ }^{* * *} \mathrm{n}=179$; apenas aqueles entrevistados que responderam que estariam dispostos a pagar mais caro pela carne rastreada foram considerados no modelo. 
A desvantagem da carne com certificação ser considerada mais cara pode ser reparada se esse produto realmente garantir que irá trazer consigo o acréscimo de algum benefício em relaçấo à carne tradicional, como citado por Dickinson; BAILEY (2005), Loureiro; Umberger (2007), Velho et al. (2009) e VERBEKE et al. (2010) ao constatarem que os consumidores estariam dispostos a pagar um valor maior do que o habitual pela carne com certificaçáo se houvessem garantias adicionais de segurança alimentar combinados com a rastreabilidade.

Assim como neste trabalho, para VerbeKe et al. (2010), os consumidores mais jovens afirmaram que para comer uma carne com qualidade estariam dispostos a pagar mais caro por isso. Entretanto, 17,43\% dos consumidores com até 40 anos não estariam de forma alguma dispostos a pagar mais caro pela carne com certificação de origem.

Dos resultados associados à renda familiar, os entrevistados que conhecem sobre a carne rastreada, ou com certificação de origem, são em sua maioria $(75,94 \%)$ consumidores que ganham mais de 7 salários mínimos. Dos consumidores com menores rendas familiares (abaixo de 6 salários mínimos), $50,40 \%$ deles conhecem sobre carne rastreada. Os consumidores que ganham 7 salários ou mais, têm 2,097 vezes mais chances de conhecerem sobre a carne rastreada ou com certificação de origem do que os indivíduos que ganham menos de 6 salários mínimos (Tabela 3).

Apesar dos consumidores com maiores rendas conhecerem sobre a rastreabilidade, vários pesquisadores concordam que isso náo influencia o aumento da credibilidade desse produto. Gellynck et al., (2006), Rijswijk; Frewer (2012), Verbeke et al. (2006) e Wezemael et al. (2010) afirmaram que as indicaçóes diretas de rastreabilidade no rótulo, tais como códigos de barras e números de licenças, assim como a falta de tempo disponível para fazer as compras dificultam a atenção por parte dos consumidores com relação à rastreabilidade.
Os resultados referentes aos consumidores de menores rendas corroboram os de GelLYNCK et al., (2006) que, em seu estudo, verificaram que $50 \%$ dos entrevistados relataram conhecer sobre a rastreabilidade; dos outros $50 \%$ participantes da pesquisa, $15 \%$ indicaram ter um conhecimento muito pobre sobre o assunto e $35 \%$ indicaram não saber realmente o que é a rastreabilidade.

$\mathrm{O}$ atributo considerado importante como fator decisivo para a compra da carne para $58,41 \%$ dos consumidores com renda maior de 7 salários mínimos é o local de compra, ou seja, estabelecimento onde a carne foi adquirida (Tabela 3). Também como foi encontrado neste estudo, Wezemael et al. (2010) afirmaram que, para a maioria dos seus entrevistados, uma boa experiência ao comprar um alimento em determinado estabelecimento influencia na sua decisão de compra da carne.

Com relaçáo ao conceito de rastreabilidade, 70,30\% dos indivíduos que ganham mais de 7 salários mínimos conhecem o conceito correto, contra $42,86 \%$ dos consumidores que ganham menos de 6 salários mínimos, ou seja, a chance de um entrevistado com renda acima de 7 salários mínimos saber o conceito correto de rastreabilidade é 2,244 vezes maior do que as chances de um consumidor que ganha menos de 6 salários mínimos saber esse conceito (Tabela 3). Assim como 70,30\% dos consumidores com maiores rendas sabem o que é carne rastreada, 70,50\% dos entrevistados da pesquisa de BarCELlos et al. (2012) também tinham conhecimento sobre a rastreabilidade. Ainda, a maioria desses entrevistados $(62,40 \%)$ disse que era a favor da rastreabilidade obrigatória da carne no Brasil.

Apesar dos indivíduos com melhores rendas familiares saberem o conceito correto de rastreabilidade, vê-se que esse não é atributo de importância relevante no momento da compra para o consumidor, como mostrado por DeNEGRI et al. (2010), ao constatarem que somente $27,5 \%$ de consumidores

Tabela 3. Questões sobre o consumo de carne bovina por consumidores que conhecem o termo carne rastreada associadas à renda familiar, em três supermercados de Belo Horizonte, Minas Gerais, Brasil, em setembro de 2012.

\begin{tabular}{|c|c|c|c|c|c|c|c|}
\hline \multirow{2}{*}{ Questão levantada* } & \multirow{2}{*}{ Renda***** } & \multicolumn{2}{|c|}{ Categorias de respostas } & \multirow{2}{*}{ Total } & \multirow{2}{*}{ Valor $\mathrm{p}$} & \multirow{2}{*}{$\begin{array}{l}\text { Odds } \\
\text { ratio }\end{array}$} & \multirow{2}{*}{ IC95\% } \\
\hline & & Não & $\operatorname{sim}(\%)$ & & & & \\
\hline \multirow{2}{*}{$\begin{array}{l}\text { Já ouviu falar sobre carne rastreada ou } \\
\text { com certificação de origem** }\end{array}$} & $\leq 6$ salários mínimos & 124 & $126(50,40)$ & 250 & \multirow{2}{*}{0,005} & 1 & $1,250-$ \\
\hline & $\geq 7$ salários mínimos & 32 & $101(75,94)$ & 133 & & 2,097 & 3,517 \\
\hline \multirow{2}{*}{$\begin{array}{l}\text { Motivo de tomada de decisão de compra: } \\
\text { local de compra (estabelecimento) }{ }^{* * *}\end{array}$} & $\leq 6$ salários mínimos & 72 & $54(42,85)$ & 126 & \multirow{2}{*}{0,001} & 1 & \multirow{2}{*}{$\begin{array}{l}1,454- \\
4,852\end{array}$} \\
\hline & $\geq 7$ salários mínimos & 42 & $59(58,41)$ & 101 & & 2,656 & \\
\hline \multirow{2}{*}{$\begin{array}{l}\text { Conceito de rastreabilidade: aquela que } \\
\text { traz informações relacionadas ao sistema } \\
\text { de produção e origem do animal** }\end{array}$} & $\leq 6$ salários mínimos & 72 & $54(42,86)$ & 126 & \multirow[b]{2}{*}{0,008} & 1 & \multirow{2}{*}{$\begin{array}{c}1,233- \\
4,084\end{array}$} \\
\hline & $\geq 7$ salários mínimos & 30 & $71(70,30)$ & 101 & & 2,244 & \\
\hline \multirow{2}{*}{$\begin{array}{l}\text { Disposição em pagar mais caro pela carne } \\
\text { bovina certificada*** }\end{array}$} & $\leq 6$ salários mínimos & 39 & $87(69,05)$ & 126 & \multirow{2}{*}{0,05} & 1 & \multirow{2}{*}{$\begin{array}{l}0,990- \\
3,510\end{array}$} \\
\hline & $\geq 7$ salários mínimos & 23 & $78(77,23)$ & 101 & & 1,864 & \\
\hline \multirow{2}{*}{$\begin{array}{l}\text { Disposto a pagar até } 10 \% \text { a mais pela } \\
\text { carne certificada**** }\end{array}$} & $\leq 6$ salários mínimos & 66 & $21(24,14)$ & 87 & \multirow{2}{*}{0,004} & 1 & \multirow{2}{*}{$\begin{array}{l}1,382- \\
5,276\end{array}$} \\
\hline & $\geq 7$ salários mínimos & 42 & $36(46,15)$ & 78 & & 2,700 & \\
\hline
\end{tabular}

IC95\%: intervalo de confiança de 95\%; *regressão logística múltipla estimada por Generalized Estimation Equations; constam apenas os fatores que permaneceram com associação estatisticamente significativa no modelo final $(p \leq 0,05) ;{ }^{* *} n=383$ entrevistados; ${ }^{* *} n=227$; apenas aqueles entrevistados que responderam que já tinham ouvido falar em carne rastreada foram considerados no modelo; **** $n=165$; apenas aqueles entrevistados que responderam que estariam dispostos a pagar mais caro pela carne rastreada foram considerados no modelo; ${ }^{* * * * *}$ cada salário mínimo $=\mathrm{R} \$ 622,00$. 
consideram importante o tratamento adequado dos animais antes do abate, regiāo de origem e sistema de rastreabilidade.

Nas duas faixas de renda analisadas, ambas estariam dispostas a pagar mais caro por um produto com certificação de origem, sendo $77,23 \%$ dos entrevistados com renda maior que 7 salários mínimos e 69,05\% dos que ganham abaixo de 6 salários mínimos. Porém, pagariam até $10 \%$ a mais pelo produto rastreado apenas $46,15 \%$ dos consumidores com maiores rendas e $24,14 \%$ dos que apresentaram menores rendas (Tabela 3 ).

OrTEga et al. (2011) observaram que a disposição em se pagar mais por informaçóes de segurança alimentar aumenta na mesma medida em que o consumidor se sente ameaçado com riscos de insegurança alimentar. Dentre os consumidores que estão dispostos a pagar mais pela carne bovina certificada, os entrevistados que ganham acima de 7 salários mínimos têm 2,70 vezes mais chances de pagar até $10 \%$ no valor final por esse produto do que indivíduos que ganham até 6 salários mínimos (Tabela 3).

No tocante aos fatores relacionados à escolaridade, 75,26\% das pessoas que conhecem sobre carne rastreada ou com certificação de origem têm graduação ou pós-graduação; esses indivíduos têm 2,464 vezes mais chances de conhecerem esse produto do que os entrevistados com escolaridade até o segundo grau completo. Dos consumidores com escolaridade até o segundo grau completo, apenas 47,66\% deles conhecem sobre carne rastreada (Tabela 4).

Esses resultados corroboram os de GELLYNCK et al. (2006), que afirmaram que enquanto as pessoas com mais escolaridade (70\%) relataram saber bem ou muito bem sobre a rastreabilidade, somente $44 \%$ das pessoas com baixa escolaridade afirmaram conhecer sobre a rastreabilidade. Segundo esses pesquisadores, os resultados demonstraram que a maior dificuldade em se ouvir falar da carne rastreada diz respeito à falta de disponibilidade e acessibilidade de informaçóes desse produto.

Ainda sobre o conhecimento sobre a rastreabilidade, BARCEllos et al. (2012) verificaram que 54,70\% dos consumidores estavam cientes sobre o sistema de rastreabilidade de carne bovina brasileira (SISBOV). No entanto, uma parte significativa dos consumidores ainda não está ciente do SISBOV, o que pode ser explicado pela falta de mecanismos institucionais para informar o público sobre rastreabilidade.

O principal atributo responsável pela tomada de decisão da compra da carne por $68,53 \%$ dos consumidores com maiores níveis de escolaridade e $54,90 \%$ com menos escolaridade é o selo de garantia de origem; ainda, 55,88\% dos consumidores com escolaridade até o segundo grau acreditam ser importante também o atributo local de compra (Tabela 4).

O conceito de rastreabilidade como sendo aquela que traz informaçôes relacionadas ao sistema de produção e origem do animal é acreditado ser correto para $65,73 \%$ dos entrevistados com terceiro grau ou mais, enquanto o conceito sendo aquela fiscalizada pelo sistema de inspeção federal ou estadual é acreditado ser o correto para 73,53\% dos entrevistados com até segundo grau completo. As chances dos consumidores que possuem graduação e pós-graduação saberem o conceito correto de rastreabilidade é 2,793 vezes maior do que os entrevistados que possuem escolaridade até o segundo grau completo (Tabela 4).

Apesar do conceito de rastreabilidade não ser bem conhecido para os entrevistados com menor grau de escolaridade, o conceito que eles escolheram traz uma impressão de segurança extra do produto, assim como relataram SCHNETTLER et al. (2009) ao observarem um alto nível de concordância sobre a inclusão de um selo de garantia de qualidade no rótulo da carne, pois, embora

Tabela 4. Questões sobre o consumo de carne bovina por consumidores que conhecem o termo carne rastreada associadas à escolaridade, em três supermercados de Belo Horizonte, Minas Gerais, Brasil, em setembro de 2012.

\begin{tabular}{|c|c|c|c|c|c|c|c|}
\hline \multirow[t]{2}{*}{ Questão levantada' } & \multirow[t]{2}{*}{ Escolaridade } & \multicolumn{2}{|c|}{$\begin{array}{l}\text { Categorias de } \\
\text { respostas }\end{array}$} & \multirow[t]{2}{*}{ Total } & \multirow[t]{2}{*}{ Valor $\mathrm{p}$} & \multirow{2}{*}{$\begin{array}{l}\text { Odds } \\
\text { ratio }\end{array}$} & \multirow[t]{2}{*}{ IC95\% } \\
\hline & & Não & $\operatorname{Sim}(\%)$ & & & & \\
\hline \multirow{2}{*}{$\begin{array}{l}\text { Já ouviu falar sobre carne rastreada ou com } \\
\text { certificação de origem }{ }^{2}\end{array}$} & Até o $2^{\circ} \mathrm{grau}$ & 112 & $102(47,66)$ & 214 & \multirow{2}{*}{0,000} & 1 & $1,531-$ \\
\hline & $3^{\circ} \mathrm{grau}$ ou mais & 47 & $143(75,26)$ & 190 & & 2,464 & 3,965 \\
\hline \multirow{2}{*}{$\begin{array}{l}\text { Motivo de tomada de decisão de compra: selo de } \\
\text { qualidade }^{3}\end{array}$} & Até o $2^{\circ} \mathrm{grau}$ & 46 & $56(54,90)$ & 102 & \multirow{2}{*}{0,018} & 1 & $1,116-$ \\
\hline & $3^{\circ} \mathrm{grau}$ ou mais & 45 & $98(68,53)$ & 143 & & 1,907 & 3,256 \\
\hline \multirow{2}{*}{$\begin{array}{l}\text { Motivo de tomada de decisão de compra: local de } \\
\text { compra (estabelecimento) }\end{array}$} & Até o $2^{\circ} \mathrm{grau}$ & 45 & $57(55,88)$ & 102 & \multirow{2}{*}{0,008} & 1 & $0,239-$ \\
\hline & $3^{\circ} \mathrm{grau}$ ou mais & 81 & $62(43,36)$ & 143 & & 0,438 & 0,803 \\
\hline \multirow{2}{*}{$\begin{array}{l}\text { Conceito de rastreabilidade: aquela que traz } \\
\text { informações relacionadas ao sistema de produção } \\
\text { e origem do animal }{ }^{3}\end{array}$} & Até o $2^{\circ} \mathrm{grau}$ & 63 & $59(57,84)$ & 102 & \multirow[b]{2}{*}{0,001} & 1 & $1,541-$ \\
\hline & $3^{\circ} \mathrm{grau}$ ou mais & 49 & $94(65,73)$ & 143 & & 2,793 & 5,063 \\
\hline \multirow{2}{*}{$\begin{array}{l}\text { Conceito de rastreabilidade: aquela fiscalizada } \\
\text { pelo sistema de inspeção federal ou estadual }{ }^{3}\end{array}$} & Até o $2^{\circ} \mathrm{grau}$ & 27 & $75(73,53)$ & 102 & \multirow{2}{*}{0,05} & 1 & $0,323-$ \\
\hline & $3^{\circ} \mathrm{grau}$ ou mais & 56 & $87(60,84)$ & 143 & & 0,571 & 1,010 \\
\hline \multirow{2}{*}{$\begin{array}{l}\text { Benefícios da carne rastreada: não apresenta } \\
\text { benefícios com relação à carne sem } \\
\text { rastreabilidade }{ }^{3}\end{array}$} & Até o $2^{\circ}$ grau & 92 & $10(9,80)$ & 102 & \multirow[b]{2}{*}{0,010} & 1 & $0,008-$ \\
\hline & $3^{\circ} \mathrm{grau}$ ou mais & 142 & $1(0,70)$ & 143 & & 0,065 & 0,515 \\
\hline
\end{tabular}

IC95\%: intervalo de confiança de 95\%; 'regressão logística múltipla estimada por Generalized Estimation Equations; constam apenas os fatores que permaneceram com associação estatisticamente significativa no modelo final ( $p \leq 0,05) ;{ }^{2} n=404$ entrevistados; ${ }^{3} n=245$; apenas aqueles entrevistados que responderam que já tinham ouvido falar em carne rastreada foram considerados no modelo. 
o regulamento sobre a produçáo dos alimentos tenha que seguir procedimentos obrigatórios para assegurar a qualidade do produto, essas informaçôes não são bem conhecidas pelos consumidores.

A maioria dos entrevistados com escolaridade até segundo grau completo $(90,20 \%)$ e acima do terceiro grau $(99,30 \%)$ concorda que a carne com certificação apresenta mais benefícios do que a carne tradicional (Tabela 4). Esses resultados são semelhantes aos verificados por CunHA et al. (2011), ao constatarem que os consumidores consideram que produtos com selo de garantia de origem são mais seguros, têm maior qualidade e são mais confiáveis.

\section{CONCLUSÕES}

Todos os fatores socioeconômicos (sexo, idade, renda e escolaridade) influenciaram na disposição de consumidores em adquirir carne bovina com certificação de origem. A maioria dos entrevistados do município de Belo Horizonte, Minas Gerais, conhece sobre carne bovina rastreada ou com certificação de origem, sendo que esses, em sua maioria, possuem renda familiar acima de sete salários mínimos, são graduados ou pós-graduados. Os atributos intrínsecos mais importantes na tomada de decisáo da carne no momento da compra foram cor, maciez, odor e pouca quantidade de gordura; enquanto que os atributos extrínsecos mais importantes foram preço, selo de qualidade e carimbo do SIF.

\section{AGRADECIMENTOS}

Ao CNPq - Conselho Nacional de Desenvolvimento Científico e Tecnológico pela bolsa de pesquisa de Lopes M. A. e Rocha, C.M.B.M.

\section{REFERÊNCIAS}

ABIEC. Associação Brasileira das Indústrias Exportadoras de Carnes. Pecuária brasileira. São Paulo, 2011. Disponível em: <http://www.abiec.com.br/3_ pecuaria.asp>. Acesso em: 10 jun. 2012.

BARCELLOS, J.O.J.; ABICHT, A.M.; BRANDÃO, F.S.; CANOZZI, M.E.A.; COLLARES, F.C. Consumer perception of Brazilian traced beef. Revista Brasileira de Zootecnia, Viçosa, v.41, n.3, p.771774,2012

BRASIL. Ministério da Agricultura, Pecuária e Abastecimento. Instrução Normativa n 1 , de 9 de janeiro de 2002. Diário Oficial da União, Brasília, 10 de janeiro de 2002. Seção 1, p.6.

BRASIL. Ministério da Agricultura, Pecuária e Abastecimento. Instrução Normativa n 17, de 13 de julho de 2006. Diário Oficial da União, Brasília, 14 de julho de 2006. Seção 1, p.23-37.

BRASIL. Ministério da Agricultura, Pecuária e Abastecimento. Instrução Normativa n 65, de 16 de dezembro de 2009. Diário Oficial da União, Brasília, 17 de dezembro de 2009a. Seção 1 , p.19-20.

BRASIL. Lei no 12.097, de 24 de novembro de 2009. Dispõe sobre o conceito e a aplicação de rastreabilidade na cadeia produtiva das carnes de bovinos e de búfalos. Diário Oficial da União, Brasília, 25 de novembro de 2009b. Seção 1, p. 2.

CAIXETA, L.G.T.; LOPES, M.A.; BRUHN, F.R.P. Não conformidades encontradas nas auditorias oficiais do SISBOV realizadas em Minas Gerais. Arquivos do Instituto Biológico, São Paulo, v.81, n.4, p.372-376. 2014
CUNHA, C.F.; SPERS, E.E.; ZYLBERSZTAJN, D. Percepção sobre atributos de sustentabilidade em um varejo supermercadista. Revista de Administração de Empresas, São Paulo, v.51, n.6, p.542-552, 2011.

DICKINSON, D.L.; BAILEY, D.V. Experimental evidence on willingness to pay for red meat traceability in the United States, Canada, the United Kingdom, and Japan. Journal of Agricultural and Applied Economics, New York, v.37, n.3, p.537-548, 2005.

FURQUIM, N.R. Food production chain identification and traceability systems: an analysis considering the perspective of a safe beef offer. In: FURQUIM, N.R. Safe food: analysis of the institutional environment for beef offer in Brazil. 2012. 157f. Tese (Doutorado) - Universidade de São Paulo, São Paulo, 2012.

GELLYNCK, X.; VERBEKE, W.; VERMEIRE, B. Pathways to increase consumer trust in meat as a safe and whole some food. Meat Science, Barking, v.74, n. 1, p.161-171, 2006.

LOPES, M.A.; SANTOS, G. Principais dificuldades encontradas pelas certificadoras para rastrear bovinos. Ciência e Agrotecnologia, Lavras, v.31, n.5, p.1552-1557, 2007.

LOUREIRO, M.L.; UMBERGER, W.J. A choice experiment model for beef: what US consumer responses tell us about relative preferences of food safety, country-of-origin labeling and traceability. Food Policy, Guildford, v.32, n.4, p.496-514, 2007.

ORTEGA, D.L;; WANG, H.H.; WU, L.; OLYNK, N.J. Modeling heterogeneity in consumer preferences for select food safety attributes in China. Food Policy, Guildford, v.36, n.2, p.318-324, 2011. 
RIJSWIJK, W.V.; FREWER, L.J. Consumer needs and requirements for food and ingredient traceability information. International Journal of Consumer Studies, New York, v.36, n.3, p.282-290, 2012.

ROCHA, C.M.B.M.; LEITE, R.C.; BRUHN, F.R.P.; GUIMARÃES, A.M.; FURLONG, J. Perceptions of milk producers from Divinópolis, Minas Gerais, regarding Rhipicephalus (Boophilus) microplus control. Revista Brasileira de Parasitologia Veterinária, Jaboticabal, v.20, n.4, p.295-302, 2011.

SCHNETTLER, B.; CIESLA, M.; CANDIA, A.; ШANCANPÁN, F.; SEPÚLVEDA J.; DENEGRI, M.; MIRANDA, H.; SEPÚLVEDA, N. Importancia del color contenido de grasa y frescura en la compra de la carne bovina en Temuco, Region de La Araucania, Chile. Revista Científica de la Facultad de Ciencias Veterinarias, Maracaibo, v.20, n.6, p.623-625, 2010.

SCHNETTLER, B.; FICA, D.; SEPÚLVEDA, N.; SEPÚLVEDA, J.; DENEGRI, $M$. Valoracion de atributos intrinsecos y extrinsecos en la compra de la carne bovina en el sur de Chile. Revista Científica de la Facultad de Ciencias Veterinarias, Maracaibo, v.20, n. 1, p.101-109, 2010.

SCHNETTLER, B.M; SILVA, R.F.; SEPÚLVEDA, N. Utility to consumers and consumer acceptance of information on beef labels in southern Chile. Chilean Journal of Agricultural Research, Santiago de Chile, v.69, n.3, p.373-382, 2009.
VELHO, J.P.; BARCELLOS, J.O.J.; LENGLER, L.; ELIAS, S.A.A.; OLIVEIRA, T.E. Disposição dos consumidores porto-alegrenses à compra de carne bovina com certificação. Revista Brasileira de Zootecnia, Viçosa, v.38, n.2, p.399-404, 2009.

VERBEKE, W.; WEZEMAEL, L.V.; BARCELLOS, M.D.; KÜGLER, J.O.; HOCQUETTE, J.F.; UELAND, O.; GRUNERT, K.G. European beef consumers' interest in a beef eating-quality guarantee: insights from a qualitative study in four EU countries. Appetite, London, v.54, n.2, p.289-296, 2010.

VERBEKE, W.; FREWER, L.J.; SCHOLDERER, J.; DE BRABANDER, H.F. Why consumers behave as they do with respect to food safety and risk information. Analytica Chimica Acta, Amsterdam, v.586, n. 1-2, p.2-7, 2006.

VERBEKE, W.; WARD, R.W. Consumer interest in information cues denoting quality, traceability and origin: an application of ordered probit models to feed labels. Food Quality and Preference, Barking, v.17, n.6, p. 453-467, 2006.

WEZEMAEL, L.V.; VERBEKE, W.; KÜGLER, J.O.; BARCELLOS, M.D.; GRUNET, K.G. European consumers and beef safety: perceptions, expectations and uncertainty reduction strategies. Food Control, Guildford, v.21, n.6, p.835-844, 2010. 